\title{
O procedimento penal por fatos de criminalidade organizada: do maxi-processo ao "grande processo»"
}

\author{
The criminal proceeding for facts of organized crime: \\ from the maxi-processo to the "big process»
}

Renzo Orlandi ${ }^{2}$

Alma Mater Studiorum - Università di Bologna, Italia

renzo.orlandi@unibo.it

https://orcid.org/0000-0002-3027-4972

\begin{abstract}
Resumo: Neste artigo são analisadas as transformações no processo penal posteriores ao maxi-processo, especificamente a formação de um processo penal especial destinado à persecução da criminalidade organizada, o "grande processo», "difuso», no qual os singulares e concretos procedimentos penais confluem, com o sério risco de perder a sua individualidade.
\end{abstract}

PalaVRAs-CHAVE: organizações criminosas; máfia; procedimento especial; técnicas especiais de investigação.

1 Relatório apresentado em Macerata, em 13 de maio de 1993, no âmbito de um encontro sobre «Luta contra a criminalidade organizada: os instrumentos normativos», organizado na Faculdade de Direito da Universidade local. O texto original foi revisado, acrescido de algumas notas essenciais e publicado na Rivista Politica del Diritto, anno XXV, n. 3, setembro de 1994, pp. 385-398, com o título original: Il procedimento penale per fatti di criminalità organizzata: dal maxi-processo al «grande processo». Tradução do italiano ao português por Luiz Eduardo Cani.

2 Professor Ordinário na Universidade de Bolonha desde 2006. Suas pesquisas são no campo das ciências penais. Os seus interesses são voltados, em particular, ao direito processual penal e à evolução dos sistemas também em perspectiva histórica e comparada. Temas preponderantemente trabalhados: prova penal, justiça penal e política, prevenção e repressão do crime organizado, análise e revisão crítica da doutrina penal e processual penal, jurisprudência em perspectiva comparada. Envolvido também, como responsável principal, em pesquisas nacionais e internacionais, mantém relações de colaboração com Universidades e Institutos de Pesquisa estrangeiros, dentre os quais, com a Pontifícia Universidade Católica do Rio Grande do Sul. 
ABSTRACT: In this article, the transformations in the criminal procedure after the maxi-processo are analyzed, specifically the formation of a special criminal procedure destined to the pursuit of organized crime, the «big process», "diffuse», in which the singular and concrete criminal proceedings come together, with the serious risk of losing his individuality.

KEYWORDs: criminal organizations; mafia; special proceeding; special investigation techniques.

\section{Consideração INTROdutória}

Esta intervenção não poderá mais do que exaurir em medida muito reduzida os argumentos evocados no título. A amplitude do tema atribuído a mim impunha uma drástica seleção das questões merecedoras de ser ilustradas. Então, considerei oportuno iniciar por aquelas mais gerais, também porque - ao que me consta - em relação a essas não houve ainda uma reflexão adequada por parte da doutrina. O que farei aqui é, portanto, um discurso geral, preliminar e uma pontual individuação e interpretação das normas processuais singulares que se referem a fatos de criminalidade organizada. É, em outras palavras, um olhar de cima e de longe, tendente a capturar as grandes linhas da recente legislação de emergência.

Com o escopo de evitar a confusão que poderia ser determinada pela sobreposição de opiniões e pontos de vista em uma matéria que pretende antes de tudo ser ordenadamente analisada, tentarei - no que for possível - abster-me de exprimir comentários e apreciações críticas: o esforço será voltado mais a compreender a razão de ser das soluções normativas que serão examinadas.

Quero começar antecipando imediatamente - por meio de teses - aquela que, na realidade, constitui a conclusão de um raciocínio e que pode ser expressa nos seguintes termos: no momento atual, os fatos subsumíveis sob a noção de criminalidade organizada são objeto de um processo judiciário que, com boa razão, se pode qualificar como especial.

Uma afirmação similar pode fundamentalmente ser sustentada a partir, em particular, da entrada em vigor do Decreto-legge n. 306, de 
8 de junho de $1992^{3}$. Quando falo de «processo judiciário especial» não aludo apenas ao tão discutido sistema do «duplo binário». Eu não sei, na verdade, o que exatamente designa essa expressão; mas é certo que vem sendo usada em uma acepção muito mais restrita do que aquela por mim proposta, se a referência é apenas as exceções (deroghe) ${ }^{4}$ relacionadas à formação contraditória (dibattimentale ${ }^{5}$ ) da prova ${ }^{6}$. Quando se fala aqui de «especialidade» do procedimento penal se pretende referir ao processo penal inteiro, a partir dos momentos iniciais - aqueles relativos à busca da notícia-crime - até a sentença que conclui o julgamento.

Se trata de ver em que consiste essa especialidade. E, a esse propósito, convém antecipar uma advertência para alertar a respeito de certas sugestões que a metáfora do duplo binário pode evocar: vale dizer, a ideia de um primeiro binário, sobre o qual continuaria a marchar o sistema (mais ou menos) acusatório, elaborado com a reforma de 1988. Eu creio que o procedimento especial do qual se fala não representa apenas um desvio (mais ou menos marcado) de um modelo acusatório, mas contém - veremos em quais termos - fortes elementos de diferenciação

3 REPÚBLICA Italiana. Testo coordinato del decreto-legge 8 giugno 1992, n. 306. Disponível em: https://www.gazzettaufficiale.it/atto/serie_generale/caricaDettaglioAtto/originario?atto.dataPubblicazioneGazzetta=1992-09-15\&atto.codiceRedazionale=092 A3636\&elenco30giorni=false. Acesso em: 21 maio 2021.

4 [N.T.] Deroghe é o plural de deroga, que, literalmente, significa derrogação. Conforme o Vocabolario della Lingua Italiana Treccani, a palavra deroga é empregada na linguagem jurídica para designar exceções ao que é estabelecido: DEROGA. In: TRECCANI. Roma: Treccani, 2021. Disponível em: https:// www.treccani.it/vocabolario/deroga. Acesso em: 21 maio 2021.

5 [N.T.] Dibattimento é a fase final do processo penal em primeiro grau, antecedida por uma audiência judicial preliminar. Equivale à audiência de instrução e julgamento brasileira. Dibattimentale designa o que diz respeito a essa fase, inclusive aos atos debatidos, de modo que pode ser traduzido por “em julgamento" ou "no julgamento". Contudo aqui trata-se da formação da prova. Falar em formação contraditória parece ser mais adequado, na medida em que não basta a apresentação da prova na audiência de julgamento. Deve-se debater para que se tenha prova. Isto é, a formação pressupõe o contraditório.

6 Quer-se aqui aludir aquele complexo de normas (como os art. 238, 468 comma 4 bis, 495 comma 1 e 511 bis do CPP) que têm o seu epicentro no art. 190 bis do CPP). 
até mesmo em relação ao modelo processual assim chamado misto, pertencente a uma tradição mais remota.

Sempre a nível de antecipação se pode dizer que o procedimento especial nos enfrentamentos ao crime organizado é o resultado (recente) de uma escolha consciente de oportunidade por parte do legislador. Faz tempo que existiu, no nosso ordenamento processual, a possibilidade de utilizar instrumentos particulares para o acertamento de certos crimes: basta pensar nas interceptações telefônicas preventivas ${ }^{7}$, na predisposição de sinergia entre atividade repressiva e preventiva ${ }^{8}$ e, ainda, nas investigações sobre patrimônios dos parentes próximos (prossimi congiunti) ${ }^{9}$ previstos na normativa especial antimáfia ${ }^{10}$ : se tratava, porém, de momentos episódicos, nos quais se podia pelo menos vislumbrar o embrião daquela organização bem mais geral e coordenada do «procedimento especial» que foi gradualmente afirmando-se no tempo, e que alcançou uma fisionomia reconhecível com os importantes eventos normativos de 1991 e de $1992^{11}$.

Para compreender em toda a sua potencialidade (portata) o «caminho» feito pelo legislador italiano, pode ser útil um paralelo com a contemporânea novela legislativa da Alemanha federal ${ }^{12}$, a qual se limita

7 Art. 226 sexies do CPP de 1930.

8 Art. 165 ter do CPP de 1930.

9 [N.T.] A definição para fins penais está prevista no art. 307 do Código Penal italiano: "Para efeitos da lei penal, entende-se por parentes próximos (prossimi congiunti) os ascendentes, os descendentes, o cônjuge, a parte de uma união civil entre pessoas do mesmo sexo, os irmãos, as irmãs, os afins no mesmo grau, os tios e sobrinhos: entretanto, na denominação de parentes próximos (prossimi congiunti), não se compreendem os afins, quando o cônjuge morreu e não há filhos."

10 Art. 25, comma 21, da Legge n. 646, de 13 de setembro de 1982.

11 Se se refere principalmente ao Decreto-legge n. 345, de 29 de outubro de 1991 (que instituiu a direção investigativa antimáfia); ao Decreto-legge n. 367, de 20 de novembro de 1991 (que instituiu a direção nacional antimáfia), e ao Decreto-legge n. 306, de 8 de junho de 1992 (sobretudo pela parte que introduz significativas exceções às regras concernentes à formação contraditória - dibbatimentale - da prova: art. 3, 7 e 9).

12 Gesetz zur Bekämpfung des Rauschgifthandels und anderer Erscheinungsformen der Organisierten Kriminalität aprovada em 15 de julho de 1992 e entrada em vigor em setembro do mesmo ano. Para informações a respeito, veja-se: 
a regular técnicas especiais de investigação em relação a fatos de criminalidade organizada, sem tocar a estrutura do julgamento ${ }^{13}$. É verdade que, no modelo processual alemão, no qual o material da investigação preliminar é destinado, em boa parte, a entrar entre as fontes cognoscitivas do órgão judicante ${ }^{14}$, potencializar o aparato investigativo público equivale, em definitivo, a influir no procedimento de formação da sentença de mérito. Mas - é preciso admitir - no ordenamento alemão as exceções ao princípio da oralidade (no entanto, maciçamente presente também no nosso sistema) valem indistintamente para todos os processos, enquanto a peculiaridade sobre a qual se quer aqui chamar atenção, é representada pela adoção, na lei italiana, de um julgamento processual especial (special procedura dibattimentale) para determinados crimes.

Se confirma, assim, a tese há pouco enunciada (e destinada a ser ulteriormente argumentada) segundo a qual, os fatos de criminalidade organizada são objeto não apenas de uma «investigação» especial (special «indagine»), mas também de um «juízo» especial (special «giudizio»): em outras palavras, de um procedimento especial geral. Mas, antes de

HILGER, Hans. Neue Strafverfahrensrecht durch das OrgKG - 1. Teil. Neue Zeitschrift für Strafrecht, ano 12, v. 10, pp. 457-463, 1992; HILGER, Hans. Neue Strafverfahrensrecht durch das OrgKG - 2. Teil. Neue Zeitschrift für Strafrecht, ano 12, v. 11, pp. 523-525, 1992.

13 A lei em questão intervém sobretudo nas indagine preliminare, regulamentando uma espécie de prática investigativa que a polícia esteve elaborando já a partir dos anos 70, na época da luta contra o terrorismo. Convém recordar, em particular, o cruzamento eletrônico de dados pessoais, voltado a individuar as pessoas a submeter à investigação (a assim chamada Rasterfahndung, então disciplinada nos §§ 98a e 98b do Strafprozeßordnung, daqui em diante, StPO); o uso de agentes de polícia «disfarçados» com falsidade ideológica (false generalità) (§§ 110a e 110e do StPO); o seguimento (pedinamento) e a observação (osservazione) a distância finalizado com a identificação do indiciado e a aquisição de informações inerentes à sua vida de relação (§ 163 e do StPO).

[N.T.] Indagine preliminare é o nome da investigação criminal estabelecida nos arts. 326 e ss. do CPP italiano (Decreto del Presidente della Repubblica n. 447, de 22 de setembro de 1988), doravante chamada de investigação preliminar. Rasterfahndung é um método computacional de procura de foragidos por meio da categorização dos suspeitos, também chamado de dragnet investigation. Strafprozeßordnung é a lei processual penal alemã.

$\S \S 251-256$ do StPO. 
ver quais aspectos caracterizam este tratamento especial, é necessário estabelecer quais casos devem ser submetidos: ou seja, é necessário ver o que significa aqui «criminalidade organizada».

\section{A NOÇÃO PROCESSUAL DE CRIMINALIDADE ORGANIZADA}

«Criminalidade organizada» é expressão indeterminada que mal se presta a individuar o pressuposto de fato para a aplicação de certas normas processuais. Apesar da necessidade de «determinação» valer sobretudo no direito penal substancial ${ }^{15}$, é preciso admitir que também no direito processual essa é aplicável, principalmente quando estão em jogo princípios ou direitos fundamentais, cuja limitação, entre outras coisas, deve quase sempre se dar por ato motivado ${ }^{16}$ da autoridade judiciária.

É, portanto, compreensível que a expressão seja usada com parcimônia nas normas concernentes à atividade processual em sentido estrito $^{17}$. Os exemplos são raros: particularmente, o art. 274, letra C, do CPP em matéria de requisitos cautelares ${ }^{18}$; o art. 240 bis das Disposizioni di attuazione del Codice di Procedura Penale (Decreto-legge n. 271, de 28 de julho de 1989), em matéria de suspensão dos prazos processuais no período de trabalho ${ }^{19}$; o art. 13 comma 1 do Decreto-legge n. 152 , de 13 de

15 Art. 25 comma 2 da Constituição da República Italiana.

16 Bem como, algumas vezes, questionável em matéria de legitimidade.

17 A respeito: Cf. CONSO, Giovanni. La criminalità organizzata nel linguaggio del legislatore. La Giustizia Penale, a. 97, n. 7, pt. III, pp. 385-392, 1992.

18 Tal disposição - como é sabido - reconhece uma exigência cautelar no concreto perigo que o indiciado cometa delitos de «criminalidade organizada». A vagueza do pressuposto deixa aflorar a dúvida que aqui a norma atribua ao magistrado um poder de escolha, não conforme a reserva legal imposta no art. 13, comma 2, da Constituição da República Italiana. A liberdade pessoal pode ser limitada apenas nos «casos previstos em lei»; e, se por casos aqui se deve entender tipos penais determinados (fattispecie criminose determinate), a previsão legal deve ser formulada de modo taxativo, através de cláusulas gerais. Na realidade, porém, a suspeita de que aquela referência à «criminalidade organizada», contida no art. 274, letra C, seja constitucionalmente ilegítima não parece fundada. A norma em questão não individualiza os casos nos quais a liberdade pessoal pode ser limitada, mas define os motivos diante dos quais tal limitação pode ser legitimamente disposta. 
maio de 1991, em tema de interceptações telefônicas ${ }^{20}$. A locução «criminalidade organizada» aparece, por outro lado, com maior frequência em algumas leis que regulam a atividade de polícia, a qual, enquanto for usada em operações informais, não precisa ser ancorada a tipos legais ( fattispecie $^{21}$ ) bem determinados ${ }^{22}$.

Nesta matéria, o princípio de determinação não é implementado com muito rigor. Apenas alguns fatos de criminalidade organizada são individuados através de referências (taxativas) a determinar hipóteses criminosas; para o resto, a lei processual se refere a uma série indeterminada de crimes, individuados através de nexos teleológicos ou causais com alguns dos tipos legais (fattispecie) taxativamente indicados. O discurso, então, se complica ulteriormente se se pensa que a lei processual não fornece, a respeito disso, uma única catalogação de crimes. Encontramos no nosso ordenamento uma multiplicidade de listas, com extensões diversas.

Uma primeira lista a tomar em conta - a mais ampla - é aquela que abrange os delitos em flagrante dos quais resulta obrigatória a prisão (art. 380 do CPP). Essa faz incidir o art. 118 do CPP que, permitindo o envio de atos e informações da autoridade judiciária ao Ministro do Interior, cria a premissa para colaboração mútua entre atividade repressiva

20 Nem mesmo aqui a indeterminação do pressuposto («criminalidade organizada») parece comportar censuras de ilegitimidade constitucional. O art. 15, comma 2, da Constituição da República Italiana admite que a liberdade de comunicação possa ser limitada «com as garantias estabelecidas em lei», e não «nos casos legalmente previstos». É, portanto, compatível com o preceito constitucional uma norma como o citado art. 13, o qual - individuando através de uma cláusula geral as hipóteses de interceptação telefônica - atribui ao magistrado o poder de fixar por quais crimes a interceptação mesma pode ser disposta.

21 [N.T.] Fattispecie é usada na linguagem jurídica para designar as circunstâncias que possuem relevância jurídica, podendo ser traduzida como hipótese de incidência da norma, como preceito normativo ou, especificamente no direito penal, como tipicidade (fattispecie oggettiva e fattispecie soggettiva) ou tipo legal (fattispecie legale). Em sentido comum, designa algum caso particular do qual se trata: FATTISPECIE. In: TRECCANI. Roma: Treccani, 2021. Disponível em: https://www.treccani.it/vocabolario/fattispecie. Acesso em: 21 maio 2021.

22 Veja-se, por exemplo, os art. 12 e 13 do Decreto-legge n. 152, de 13 de maio de 1991 (institutivo dos serviços centrais e interprovinciais de polícia), bem como os art. 2, 3 e 4 do Decreto-legge n. 345, de 29 de outubro de 1991 (institutivo da direção investigativa antimáfia). 
e atividade preventiva. A mesma incidência se encontra no art. 270 do $\mathrm{CPP}$, como limite à possibilidade de utilizar os êxitos da interceptação telefônica efetuada em outros procedimentos; e no art. 9 do Decreto-legge n. 8, de 15 de janeiro de 1991, como um dos pressupostos para a adoção de medidas idôneas a assegurar a incolumidade dos colaboradores da justiça.

Outra lista de crimes relevante para os nossos objetivos é aquela contida no art. 275 comma 3 do CPP, que fixa uma espécie de presunção iuris tantum quanto à subsistência de requisitos cautelares aptos a justificar a custódia no cárcere. $\mathrm{E}$ a mesma norma se referem, por exemplo, a disposição que atribui ao procurador nacional antimáfia o poder de dispor sobre a permanência cautelar (soggiorno cautelare ${ }^{23}$ ) (art. 25 quarter do Decreto-legge n. 306 de 1992), e as disposições sobre a matéria em termos de duração da investigação preliminar: notadamente o art. 407 comma 2, letra A, do CPP, por sua vez complementado pelo art. 405, comma 2, do CPP.

Enfim, deve ser mencionada a lista contida no art. 51, comma 3 bis, do CPP, elaborada para fixar os limites de atribuição da procuradoria distrital antimáfia. A mesma norma é também expressamente complementar de numerosas outras disposições, entre as quais merecem ser particularmente recordados o art. 190 bis do CPP em matéria de direito à prova oral; o art. 371 bis do CPP em matéria de atividade do procurador nacional antimáfia; o art. 406, comma 5 bis, do CPP concernente às modalidades de concessão de prorrogação na investigação preliminar.

A lista de crimes do art. 51, comma 3 bis, do CPP acaba sendo a mais reduzida, e é formulada em modo tal para ser abrangida por inteiro nas duas listas precedentes. Se pode, portanto, dizer que nos procedimentos relativos aos crimes elencados na norma em questão valem seja as regras especiais que se vinculam expressamente a tal norma, seja aquelas previstas para os procedimentos relativos às outras, como no mencionado rol de crimes (art. 118, 275, 406 e 407 do CPP). É sobretudo com relação aos crimes indicados no art. 51, comma 3 bis, do CPP que se verifica o

23 [N.T.] O art. 16 da Constituição da República Italiana reconhece o direito à liberdade para que os cidadãos possam circular e permanecer (soggiornare) livremente. A medida de soggiorno cautelare consiste na determinação, pelo procurador nacional antimáfia, de local onde o imputado deve se estabelecer e das condições que deve cumprir. 
maior número de desvios da disciplina processual ordinária. São também estes os crimes que compõem a noção processual de criminalidade organizada $^{24}$, e é mesmo em relação a esses que se delineia a existência de um «procedimento especial», no sentido há pouco mencionado.

\section{Delitos de CRIMINAlidade organizada E Conotações RELEVANTES PARA A LEGISLAÇÃO PROCESSUAL ESPECIAL}

Não há dúvida que as disposições especiais aplicáveis aos delitos indicados no art. 51, comma 3 bis, do CPP são o resultado de escolhas de oportunidade. Todavia, embora aqui a discricionariedade legislativa desempenhe um papel decisivo, é difícil escapar da impressão que algumas daquelas escolhas foram impostas por uma espécie de prepotente «natureza das coisas», quase como se a eficaz perseguição do crime organizado impusesse fatalmente uma adequação da normativa processual ${ }^{25}$. É lícito, então, supor que o conceito de «criminalidade organizada», embora vago e indefinido, forneceu a justificação lógica para uma série de desvios «razoáveis» da normativa ordinária ${ }^{26}$. Daquele conceito as-

24 Prescinde-se aqui de considerar o delicado problema inerente a definição de uma noção que, além de tudo, permanece cercada de um halo de indeterminação. O elenco fornecido no art. 51, comma 3 bis, do CPP satisfaz aqueles requisitos de precisão objetiva que as escolhas normativas ligadas a isso teriam aconselhado: ao reduzido repertório de crimes individuados através da referência ao nomen iuris (art. 416 bis e 630 do CP, bem como art. 74 do Decreto del Presidente della Repubblica n. 309, de 9 de outubro de 1990), soma-se a referência a uma série indefinida de tipos penais (fattispescie criminose), cuja característica consiste em estar em uma relação instrumental ou teleológica com uma associação de tipo mafioso.

25 Salienta as «peculiaridades objetivas e subjetivas» dos procedimentos relativos à criminalidade organizada e a consequente inadequação da normativa processual produzida na reforma de 1988: GREVI, Vittorio. Nuovo codice di procedura penale e processi di criminalità organizzata: un primo bilancio. In: GREVI, Vittorio (Org.). Processo penale e criminalità organizzata. Bari: Laterza, 1993, p. 6.

26 Nesta perspectiva, o nome «criminalidade organizada» desvela um significado tipicamente funcional, pragmaticamente orientado: uma expressão que designa unitariamente aquela série indefinida de fenômenos idôneos a justificar a introdução no sistema de institutos processuais especiais e de técnicas de investigação particulares. Não é distinto, em definitivo, o ponto de vista 
sume relevância, em particular, algumas conotações fundamentais, que convém brevemente analisar, a fim de compreender a razão de ser e o escopo inovador das escolhas mencionadas acima.

\section{A. OMERTÀ ${ }^{27}$}

O caráter silencioso dos fenômenos criminais torna necessária a predisposição de atividade investigativa inspirada em rigorosos critérios de segredo (também interno) e estruturados de modo a assegurar o efeito surpresa da operação. Os exemplos são numerosos e se relacionam a uma variada tipologia de instrumentos investigativos: as interceptações de conversas são admitidas com maior facilidade quando se trata de crimes de criminalidade organizada ${ }^{28}$; as buscas podem ser excepcionalmente conduzidas em edifícios ou blocos de edifícios inteiros ${ }^{29}$; às vezes as inspeções e buscas podem ser utilizadas até mesmo antes da notícia-crime, tornando-se, assim, instrumentos de investigação da notícia mesma ${ }^{30}$; podem também ser lembradas as atividades de investigação secreta que consistem em seguir e observar informalmente à distância, possíveis nos casos que a lei admite que seja retardada a execução da medida cautelar

que afirma que o conceito em questão abrange o conjunto das manifestações criminosas que os órgãos investigativos seriam incapazes de perseguir com o uso das temáticas tradicionais de investigação: Por exemplo, Cf. BUSCH, Heiner. Organisierte Kriminalität: vom Nutzen eines unklaren Begriffs. Demokratie und Recht, v. 20, n. 4, pp. 375-395, 1992, p. 375 e 383.

[N.T.] Omertà é o nome dado à lei do silêncio da Camorra. Atualmente, usa-se a palavra para designar um pacto de silêncio que vise preservar a identidade do autor de um crime: OMERTÀ. In: TRECCANI. Roma: Treccani, 2021. Disponível em: https://www.treccani.it/vocabolario/omerta. Acesso em: 21 maio 2021.

Em particular, o art. 13 do Decreto-legge n. 152, de 13 de maio de 1991, simplifica os pressupostos para o cumprimento do ato; o art. 25 ter do Decreto-legge n. 306, de 8 de junho de 1992, admite, ao invés, que a interceptação possa ser disposta com a dúplice finalidade de prevenir os crimes indicados no art. 51, comma 3 bis, do CPP e de obter informações acerca desses.

29 Art. 25 bis do Decreto-legge n. 306, de 8 de junho de 1992.

30 Art. 27, da Legge n. 55, de 19 de março de 1990, bem como art. 103 do Decreto del Presidente della Repubblica n. 309, de 9 de outubro de 1990. 
(pessoal ou real) ${ }^{31}$; o uso de agentes provocadores ${ }^{32}$ e, sobretudo, o recurso maciço aos «colaboradores da justiça», tornado possível por uma legislação complexa de natureza marcadamente recompensadora ${ }^{33}$. Parece significativa também a regra especial em tema de prorrogação dos prazos de investigação preliminar (art. 406, comma 5 bis, do CPP), segundo a qual a pessoa indiciada por um dos crimes elencados no art. 51, comma 3 bis, do CPP, pode não ser comunicada sobre eventuais prorrogações ${ }^{34}$.

\section{B. Periculosidade}

O conceito de criminalidade organizada caracteriza-se, então, pela ideia de «perigo grave» que evoca. Prescindimos de qualquer evidência em torno do uso político-ideológico ao qual esta conotação, sem dúvida, se presta. Interessa aqui, em vez disso, evidenciar a consequência jurídico-processual do conceito. Sob esse ponto de vista, a conotação de periculosidade intrínseca aos fenômenos de criminalidade organizada justifica (no plano da razoabilidade) uma limitação particularmente marcada dos direitos fundamentais da pessoa. Também aqui os exemplos abundam na nossa legislação: basta pensar, no que concerne à liberdade pessoal, na norma que fixa um tipo de presunção iuris tantum em matéria

31 Art. 98 do Decreto del Presidente della Repubblica n. 309, de 9 de outubro de 1990; art. 10 do Decreto-legge n. 419, de 31 de dezembro de 1991; art. 12 quater, comma 3, do Decreto-legge n. 306, de 8 de junho de 1992.

32 Art. 97 do Decreto del Presidente della Repubblica n. 309, de 9 de outubro de 1990; art. 12 quater, commi 1, 2 e 4, do Decreto-legge n. 306, de 8 de junho de 1992.

33 Merecem ser recordados, a este propósito, não apenas as normas que estabelecem reduções de pena para quem se dispõe a colaborar (art. 8 do Decreto-legge n. 152, de 13 de maio de 1991), mas também aquelas que reservam um tratamento penitenciário mais favorável aos condenados dispostos a colaborar (art. 4 bis e 58 ter da Legge n. 354, de 26 de julho de 1975), bem como aquelas que permitem a adoção de programas e medidas para salvaguardar a incolumidade de certas pessoas (art. 9-15 do Decreto-legge n. 8, de 15 de janeiro de 1991, e o Decreto-legge n. 119, de 29 de março de 1993).

34 Para uma análise das práticas investigativas à luz das normas especiais de emergência, veja-se: MADDALENA, Marcello. I problemi pratici delle inchieste di criminalità organizzata nel nuovo processo penale. In: GREVI, Vittorio. (Org.). Processo penale e criminalità organizzata. Bari: Laterza, 1993, p. 79 e ss. 
de subsistência dos requisitos cautelares para dispor da custódia no cárcere $^{35}$, e aquela que dita, de fato, uma regra particular de suspensão dos prazos da custódia cautelar ${ }^{36}$. Com relação a liberdade de domicílio, a experimentabilidade (esperibilità ${ }^{37}$ ) das buscas é admitida com uma certa largura dos pressupostos, como já dito ${ }^{38}$; a liberdade e sigilo das comunicações pode ser limitada com maior facilidade do que nos casos ordinários, quando se trata de acertar fatos de criminalidade organizada ${ }^{39}$, ou quando se trata de investigar uma pessoa fugitiva em relação a tais fatos ${ }^{40}$. No que concerne, enfim, ao direito de defesa, vale a pena mencionar sobretudo a severa restrição ao contraditório prevista no art. 190 bis do CPP. Esta norma - também a julgar pela sua colocação topográfica - parece-nos como limitação ao direito de defesa do imputado e, mais precisamente, àquela particular manifestação da garantia defensiva representada pelo direito à prova oral. É, portanto, a suposta gravidade do crime - embora seja considerada como a necessidade de evitar a «usura do testemunho ${ }^{41}$ que justifica o sacrifício ao direito fundamental.

Retornaremos em breve a esta disposição, a propósito da qual, porém, vale a pena fazer imediatamente um esclarecimento. Em realidade, não se pode dar como certo que seja apenas uma exceção ao direito de defender-se provando; ou seja, seria reducionista vermos uma simples erosão das garantias defensivas, visando tornar possível um acertamento da verdade mais rápido e, ao mesmo tempo, mais confiável. Se considerarmos bem, o art. 190 bis do CPP contraria, invertendo os termos, o

35 Art. 275, comma 3, do CPP.

36 Art. 304, comma 2, do CPP, também em relação ao art. 297, comma 4, do CPP.

37 [N.T.] O verbo esperire designa o que pode ser tentado, provado, experimentado. Relaciona-se ao trabalho de peritos, mas também ao que pode ser objeto de prova, ou seja, as tentativas ou as direções das perícias: ESPERIRE. In: TRECCANI. Roma: Treccani, 2021. Disponível em: https://www.treccani.it/ vocabolario/esperire. Acesso em: 21 maio 2021.

38 Veja-se as normas supracitadas nas notas 28 e 29.

39 Veja-se as normas supracitadas na nota 26.

40 Art. 295, comma 3 bis, do CPP.

41 [N.T.] A expressão italiana «usura del testimone» designa um desgaste dos testemunhos devido às inquirições repetidas, durante vários anos. Os principais problemas desse desgaste são a contaminação das memórias e a contaminação cruzada das provas. 
paradigma de gnoseologia judiciária subjacente ao precedente art. 190 do CPP; aquele, precisamente, que reconhece na oralidade e no contraditório, a regra para chegar à decisão. Se pode dizer que para o art. 190 bis do CPP é a prova escrita que constitui a regra, enquanto aquela oral deve ser admitida apenas se o juiz a considera «absolutamente necessária». Mais que uma atenuação de garantias defensivas, isso faz, portanto, uma exceção ao princípio da oralidade. Uma exceção sem justificação lógica se se considera que o contraditório vale sobretudo como melhor método para aproximar-se da verdade. De fato, se garantir a defesa nos termos previstos do art. 190 do CPP abrangesse o risco de afastar-se da verdade, seria razoável adotar o método sugerido no art. 190 bis do CPP em relação a qualquer caso a julgar (regiudicand $a^{42}$ ), sem distinção de qualquer tipo. Se, ao contrário, fosse o direito à prova oral - como previsto no art. 190 do CPP - a garantir uma melhor aproximação à verdade, seria ilógico e irrazoável renunciar ao método mais confiável justo quando se trata de acertar fatos graves e severamente punidos, vale dizer, justo quando - sendo tão elevada a aposta em jogo - se recomendaria a maior circunspeção no ato de julgar. Mas a contradição deixa de existir para quem - como já referido - considera que o contraditório é uma simples expressão do direito de defesa, suscetível de ser limitado diante da necessidade de perseguir fatos de notável periculosidade ${ }^{43}$. E é apenas com base em uma suposição semelhante que se pode justificar, do ponto de vista da razoabilidade, uma disposição como aquela do art. 190 bis do CPP.

42 [N.T.] Regiudicanda é o equivalente italiano à expressão latina res judicanda que designa a coisa que ainda pende de julgamento. Em português, pode-se recorrer ao conteúdo (ou objeto, a depender da concepção) do processo penal que aguarda julgamento. Daí porque optou-se por caso a julgar, partindo da proposta de caso penal como conteúdo do processo penal: COUTINHO, Jacinto Nelson de Miranda. A lide e o conteúdo do processo penal. 2. ed. Curitiba: Juruá, 1998.

43 Pode-se, em definitivo, afirmar que - com o art. 190 bis do CPP - o legislador caiu no equívoco eficazmente denunciado por: FERRUA, Paolo. Contraddittorio e verità nel processo penale. In: FERRUA, Paolo. Studi sul processo penale: Anamorfosi del processo accusatorio. Turim: Giappichelli, 1992, v. 2, p. 47 e ss. O equívoco consistente em conceber o contraditório e o direito à prova oral como simples garantias individuais, cuja tutela residiria em exigências políticas ao invés de em razões de caráter epistemológico (como dito por: UBERTIS, Giulio. La ricerca della verità giudiziale. In: UBERTIS, Giulio. (Org.). La conoscenza del fatto nel processo penale. Milão: Giuffrè, 1992, p. 31 e ss.). 


\section{DIFUSÃo}

Ao caráter difuso da criminalidade organizada se unem as novidades mais significativas da normativa processual especial. O termo «difusão» é aqui entendido em, pelo menos, três acepções distintas.

Antes de tudo, em sentido espacial. $\mathrm{O}$ fato que a atividade das organizações criminosas se tornou progressivamente a mesma no território nacional inteiro e até mesmo além de suas fronteiras, tornou obsoletas as tradicionais repartições territoriais dos ofícios judiciários. A este fenômeno foram combinadas, em um primeiro momento, as disposições normativas permissivas de trocas de informações para fins de coordenação investigativa entre órgãos de investigação ${ }^{44}$. Por sua parte, a reforma processual de 1988 havia reforçado os instrumentos de coordenação entre ofícios do Ministério Público ${ }^{45}$, mas de uma maneira que logo pareceu inadequada para atingir os escopos desejados ${ }^{46}$. Se previne assim, mesmo entre debates acalorados e polêmicas, a preparação de mecanismos adicionais e mais eficazes de coordenação, que culminaram - como é conhecido - na apresentação de uma série de provimentos normativos destinados, por um lado, a melhor coordenar a atividade de polícia através da instituição de forças conjuntas para serviços especiais e da direção investigativa antimáfia ${ }^{47}$ e, por outro lado, a racionalizar a atividade do ofício de acusação através da instituição das procuradorias distritais e da procuradoria nacional antimáfia ${ }^{48}$. Mas a difusão territorial

44 Já no CPP anterior o rito estavam presentes disposições desse tipo: art. 165 bis e 165 ter inseritos no CPP de 1930 por meio do art. $4^{\circ}$ do Decreto-legge n. 59, de 21 de março de 1978.

45 Principalmente os art. 117 e 371 do CPP.

46 Veja-se, por exemplo, os sintéticos, mas densos, comentários dedicados ao problema por: VIOLANTE, Luciano. Il nuovo processo penale e la criminalità mafiosa. Relazione della Commissione parlamentare antimafia. Cassazione penale, 1990, p. 2047-2048.

47 Art. 12 do Decreto-legge n. 152, de 13 de maio de 1991, e Decreto-legge n. 345, de 29 de outubro de 1991.

48 Art. 51, comma 3 bis, e 371 bis do CPP, bem como art. 70 bis do Regio-decreto n. 12, de 30 de janeiro de 1941 (Ordenamento judiciário). Cf., por fim, o argumento: TURONE, Giuliano. Indagini collegate, procure distrettuali e procura nazionale antimafia. In: GREVI, Vittorio. (Org.). Processo penale e criminalità organizzata. Bari: Laterza, 1993, p. 141 e ss. 
da atividade criminosa não produziu efeitos apenas sobre a organização da atividade investigativa e sobre a estrutura do ofício de acusação. Essa terminou por contaminar até a atividade decisória, desde o momento que, também no nosso ordenamento processual, os êxitos da investigação preliminar têm muita probabilidade de transformar-se em provas úteis para o julgamento. Mormente nos processos por fatos de criminalidade organizada, nos quais as linhas de continuidade entre as duas fases se tornaram, de fato, notáveis. Graças ao já referido art. 190 bis do CPP, a cesura entre investigação (indagine) e julgamento (dibbattimento) resta atenuada em relação aos procedimentos, por assim dizer, ordinários. Mas é sobretudo a separação entre diversos procedimentos a sair mais relativizada, pois a norma em questão tende a abolir as delimitações entre um acertamento e outro, favorecendo a circulação de material probatório e a sua utilização em uma série indeterminada de julgamentos (principalmente os art. 238, 238 bis e 511 bis do CPP e o art. 78 das Disposizioni di attuazione del Codice di Procedura Penale).

As organizações criminosas se caracterizam, entre outras coisas, pela sua difusão temporal. Os fatos de criminalidade organizada têm a dúplice característica de serem conhecidos (embora genericamente) pelos órgãos de investigação (polícia e Ministério Público) antes mesmo de se tornarem objeto de um procedimento penal, e de continuarem a manifestar-se depois desse momento. Entra, assim, definitivamente em crise a clássica distinção entre atividade preventiva e atividade repressiva. Por um lado, o processo se enriquece de institutos sempre mais claramente voltados a satisfazer finalidades preventivas ${ }^{49}$. Por outro lado, e sobretudo, é fácil constatar que a atividade assim chamada preventiva tende progressivamente a fundir-se com aquela repressiva, até que se confunda com esta. Basta pensar em institutos como a interceptação

49 A observação aplica-se genericamente, isto é, para todos os procedimentos penais qualquer que seja o caso a julgar (regiudicanda) em questão, como demonstra a circunstância que as disposições em matéria de medidas cautelares orientadas em sentido preventivo (principalmente o art. 274, letra c; art. 321; art. 287-290; art. 312-313 do CPP), são formuladas sem referência a particulares categorias de crimes. Mesmo assim, justo a assinalada difusão temporal do fenômeno, faz com que as normas como aquelas citadas encontrem aplicação especialmente em relação a fatos de criminalidade organizada. 
telefônica preventiva ${ }^{50}$, ou as inspeções e buscas especiais admitidas sob o pressuposto de uma simples suspeita de que determinadas atividades criminosas estão sendo desenvolvidas ${ }^{51}$. Parece, ainda, significativo a esse respeito que as «entrevistas investigativas» (colloqui investigativi ${ }^{52}$ ) com os colaboradores da justiça são simultaneamente postos sob o controle de órgãos do executivo que têm atribuições de prevenção criminal (Ministro do Interior, chefe da polícia) e de um magistrado (procurador nacional antimáfia) ${ }^{53}$. A singularidade dos atos e operações preventivas com caráter repressivo reside nisto: que não pressupõem necessariamente a existência de uma notícia-crime, ainda assim servem (ou podem servir, se for o caso) a preparar o terreno para uma futura atividade de investigação penal (indagine penale). Apesar de a lei não indicar expressamente a finalidade preventiva, estes meios investigativos especiais ante dictum se transformam fatalmente - nas mãos dos órgãos de polícia - em instrumentos para obter elementos úteis ao prosseguimento de investigações já em curso e, o mais importante, para buscar ativamente novas notícias-crime, vale dizer, para obter o pressuposto de fato de um novo procedimento penal.

Temos, por fim, um outro tipo de «difusão» relacionada aos fenômenos de criminalidade organizada e que tem grande importância nesse contexto específico: se alude à atitude própria das condutas criminosas aqui consideradas para condicionar a atividade, por si lícita, da vida de relação social. A articulada ramificação do crime organizado e suas numerosas interferências especiais com a vida econômica e política, tiveram consequências marcantes no terreno processual. Contam-se agora numerosas disposições especiais que legitimam o magistrado a regular situações externas ao processo com provimentos provisórios, ou, de qualquer maneira, ainda suscetíveis de ser modificados. Por exemplo, é suficiente a submissão a procedimento de prevenção criminal ou a procedimento penal, o reenvio a julgamento ou a condenação em apelação

\footnotetext{
50 Art. 225 das Disposizioni di attuazione del Codice di Procedura Penale e art. 25 ter do Decreto-legge n. 306, de 8 de junho de 1992.

51 Veja-se, a esse respeito, o já citado art. 27, comma 2, da Legge n. 55, de 19 de março de 1990, e o art. 103 do Decreto del Presidente della Repubblica n. 309, de 9 de outubro de 1990.

52 [N.T.] Modalidade de entrevista com suspeitos de crimes.

53 Art. 18 bis da Legge n. 354, de 26 de julho de 1975.
} 
(não definitiva), porque automaticamente extingue-se o direito a ser candidato nas eleições locais ${ }^{54}$, ou porque determinam-se preclusões no campo das autorizações administrativas ${ }^{55}$, ou, ainda, nos organogramas de certas instituições de crédito $^{56}$. Ao mesmo tempo, acentua-se o uso em função preventiva, também ante delictum, de tradicionais medidas cautelares ou de segurança: pense-se no sequestro de bens determinado nas normas dos art. 2 bis e 2 ter da Legge n. 575, de 31 de maio de 1965; ao estabelecimento cautelar (soggiorno cautelare) ex art. 25 quarter do Decreto-legge n. 306, de 8 de junho de 1992; ao confisco de bens (art. 2 ter, comma 3, da Legge n. 575, de 31 de maio de 1965).

Põe-se aqui um problema de porte notável, que não toca apenas à relação entre atividade preventiva e atividade repressiva, mas envolve até a mais geral relação entre juiz e lei. Tradicionalmente, o juiz pode regular situações externas ao processo através da sentença definitiva, ou, em qualquer caso, com a adoção de provimentos também provisórios, mas sujeitos a exame de legitimidade pela Corte de Cassação ${ }^{57}$. Em relação a muitos dos provimentos referidos acima constata-se, ao invés disso, que as decisões com julgamento de mérito se refletem imediatamente sobre delicadas situações externas ao processo, sem que a esse correspondam controles específicos em sede de impugnação. E também quando esses controles são previstos (como acontece, por exemplo, para as medidas cautelares citadas), a sua eficácia é, em qualquer caso, escassa, considerada a vagueza dos pressupostos de fato com base nos quais o relativo provimento pode ser adotado (pense-se na «notável desigualdade entre o padrão de vida e a quantidade de renda», ou no fundado motivo que o sujeito está prestes a cometer um determinado delito), e a consequente dificuldade para revisar eventual error in iudicando.

54 Art. 15 da Legge n. 55, de 19 de março de 1990.

Art. 10 da Legge n. 575, de 31 de maio de 1965.

57 A qual teria, teoricamente, a atribuição de assegurar a exata observância da lei (art. 65, comma 1, do Regio-decreto n. 12, de 30 de janeiro de 1941), assim evitando a produção de um direito judiciário paralelo ou alternativo àquele legal. 


\section{Conclusão}

É hora de puxar os fios das considerações, embora rápidas, desenvolvidas até aqui. O quadro que emerge é aquele de uma legislação processual, que tende fatalmente a adequar as próprias regras ao caráter «difuso» e «perigoso» do crime organizado, trazendo, assim, à existência um modelo «especial» de procedimento.

Especial é o modo em que são obtidas as notícias-crime: não passivamente recebidas pelas forças de polícia, mas buscadas de maneira ativa e constante graças à predisposição de um aparato de autoabastecimento que tem os seus pontos fortes na coordenação centralizada das iniciativas investigativas (direção investigativa antimáfia), no uso de instrumentos de investigação ante delictum (como as interceptações, inspeções e buscas preventivas, assim como as entrevistas investigativas com colaboradores da justiça).

Especial é, ainda, a organização do ofício de acusação, articulado nas vinte e seis direções distritais antimáfia, bem como controlado e coordenado a nível central pela correspondente direção nacional.

Especiais são, então, as atribuições cautelares do juiz neste tipo de procedimento, no qual necessidades repressivas e preventivas se apresentam assim estreitamente entrelaçadas.

Especiais, enfim, são as regras a seguir para a formação do julgamento como atestam, em particular, as exceções ao princípio da oralidade e do contraditório: vale dizer, as disposições dos art. 190 bis, 468, comma 4, 495, comma 1, do CPP, bem como aquelas dos art. 238, 238 bis e 511 bis que - apesar de relacionadas à generalidade dos casos a julgar (regiudicande) - são, de fato, destinadas a encontrar aplicação em um número limitado de casos.

O que se impõe evidentemente é a totalidade desta especialidade processual: o alegado caráter unitário da criminalidade organizada induziu o legislador a organizar unitariamente não apenas a investigação (indagine) da polícia e a função de acusação, mas até mesmo a atividade probatória e, portanto, o juízo.

É mesmo nesta qualidade, por assim dizer, transitiva dos meios de prova, que se captura o aspecto talvez saliente do processo especial. Parece superado o assunto - pacífico, ao invés disso, por quem pensa 
com base nos paradigmas do sistema acusatório ${ }^{58}$ - segundo o qual cada processo constitui uma história autônoma, de modo tal a dizer respeito apenas aos imputados diretamente envolvidos, e não a outros imputados nem, em todo caso, ao acertamento de outros casos a julgar (regiudicande). Ao contrário: no modelo aqui considerado, o processo singular ( ingolo processo $0^{59}$ ) não é voltado principalmente a afirmar a justiça do caso nesse discutido, sendo, em vez disso, concebido como meio para atingir um fim que transcende a solução daquele mesmo caso: um fim (político) genericamente identificável na luta contra o crime organiza$\mathrm{do}^{60}$. Em outras palavras, o processo singular termina com a perda da sua unidade, confrontando-se como fragmento de uma totalidade articulada e complexa: parte de uma espécie de grande processo virtual, definível como a soma de uma série indeterminada de assuntos legais (vicende giudiziarie $^{61}$ ) concretos, entre si ligados pelo fato de se referirem a uma realidade criminosa que, no fundo, presume-se ser sempre a mesma.

No lugar do assim chamado «maxi-processo» ${ }^{62}$, elevado a emblema da luta contra o crime organizado na anterior codificação ${ }^{63}$, temos hoje aquele que pode ser definido como o «grande processo»: um processo «difuso», no qual os singulares e concretos procedimentos penais confluem, com o

$58 \mathrm{Ou}$, melhor, para quem, vendo no processo uma «técnica de resolução dos conflitos», é induzido a acentuar a importância das regras processuais, a ponto de considerá-las o autêntico pressuposto fundante da decisão de mérito: Cf. DAMAŠKA, Mirjan. I volti della giustizia e del potere. Analisi comparatistica del processo. Bolonha: Il Mulino, 1991, p. 179-182 (principalmente).

59 [N.T.] Optou-se por traduzir literalmente, embora se possa falar em processo único, processo individual, único processo, processo particular, processo determinado, processo sozinho etc.

${ }^{60}$ Não se tem, com essas palavras, a intenção de avalizar, nem de rejeitar a solução legislativa. Como já advertido anteriormente, importa neste texto individuar e descrever o processo especial que a lei instituiu para reprimir os fenômenos adequados à noção de criminalidade organizada. Se se exime, portanto, de análises ou apreciações críticas das normas positivas.

${ }^{61}$ [N.T.] Vicende é o plural de vicenda que, por sua vez, designa uma série de coisas ou fatos, evento ou série de eventos, casos, episódios fatos, histórias etc. Vicenda giudiziaria designa as matérias levadas a julgamento (legal matters).

62 [N.T.] Expressão criada pela mídia italiana para designar o processo contra a máfia da Sicília (Cosa Nostra), que tramitou em Palermo, entre o fim da década de 1980 e o início da década de 1990, e se desenvolveu em face de 475 imputados.

[N.T.] Código de Processo Penal italiano de 1930. 
sério risco de perder a sua individualidade. Disso, de resto, encontramos uma sugestiva confirmação na regra segundo a qual a sentença penal pode ser utilizada como prova no julgamento do fato (art. 238 bis do CPP). Esta norma singular - vendo bem - encontra sua justificação lógica justo na ideia de um «grande processo», a respeito do qual as sentenças dos julgamentos de mérito valem essencialmente pela contribuição informativa que são capazes de fornecer para o conhecimento daquela realidade criminosa «única».

\section{REFERÊNCIAS}

BUSCH, Heiner. Organisierte Kriminalität: vom Nutzen eines unklaren Begriffs. Demokratie und Recht, v. 20, n. 4, pp. 375-395, 1992.

CONSO, Giovanni. La criminalità organizzata nel linguaggio del legislatore. $L a$ Giustizia Penale, a. 97, n. 7, pt. III, pp. 385-392, 1992.

DAMAŠKA, Mirjan. I volti della giustizia e del potere. Analisi comparatistica del processo. Bolonha: Il Mulino, 1991.

FERRUA, Paolo. Contraddittorio e verità nel processo penale. In: FERRUA, Paolo. Studi sul processo penale: Anamorfosi del processo accusatorio. Turim: Giappichelli, 1992, v. 2.

GREVI, Vittorio. Nuovo codice di procedura penale e processi di criminalità organizzata: un primo bilancio. In: GREVI, Vittorio. (Org.). Processo penale e criminalità organizzata. Bari: Laterza, 1993.

HILGER, Hans. Neue Strafverfahrensrecht durch das OrgKG - 1. Teil. Neue Zeitschrift für Strafrecht, ano 12, v. 10, pp. 457-463, 1992.

HILGER, Hans. Neue Strafverfahrensrecht durch das OrgKG - 2. Teil. Neue Zeitschrift für Strafrecht, ano 12, v. 11, pp. 523-525, 1992.

MADDALENA, Marcello. I problemi pratici delle inchieste di criminalità organizzata nel nuovo processo penale. In: GREVI, Vittorio. (Org.). Processo penale e criminalità organizzata. Bari: Laterza, 1993.

REPÚBLICA Italiana. Testo coordinato del decreto-legge 8 giugno 1992, n. 306. Disponível em: https://www.gazzettaufficiale.it/atto/serie_generale/caricaDettaglioAtto/originario?atto.dataPubblicazioneGazzetta=1992-09-15\&atto. codiceRedazionale=092A3636\&elenco30giorni=false. Acesso em: 21 maio 2021. TURONE, Giuliano. Indagini collegate, procure distrettuali e procura nazionale antimafia. In: GREVI, Vittorio. (Org.). Processo penale e criminalità organizzata. Bari: Laterza, 1993. 
UBERTIS, Giulio. La ricerca della verità giudiziale. In: UBERTIS, Giulio. (Org.). La conoscenza del fatto nel processo penale. Milão: Giuffrè, 1992.

VIOLANTE, Luciano. Il nuovo processo penale e la criminalità mafiosa. Relazione della Commissione parlamentare antimafia. Cassazione penale, 1990.

\section{REFERÊNCIAS DA TRADUÇÃO}

COUTINHO, Jacinto Nelson de Miranda. A lide e o conteúdo do processo penal. 2. ed. Curitiba: Juruá, 1998.

DEROGA. In: TRECCANI. Roma: Treccani, 2021. Disponível em: https://www. treccani.it/vocabolario/deroga. Acesso em: 21 maio 2021.

ESPERIRE. In: TRECCANI. Roma: Treccani, 2021. Disponível em: https://www. treccani.it/vocabolario/esperire. Acesso em: 21 maio 2021.

FATTISPECIE. In: TRECCANI. Roma: Treccani, 2021. Disponível em: https:// www.treccani.it/vocabolario/fattispecie. Acesso em: 21 maio 2021.

OMERTÀ. In: TRECCANI. Roma: Treccani, 2021. Disponível em: https://www. treccani.it/vocabolario/omerta. Acesso em: 21 maio 2021.

\section{Additional information and author's declarations (scientific integrity)}

Conflict of interest declaration: the author confirms that there are no conflicts of interest in conducting this research and writing this article.

Declaration of authorship: all and only researchers who comply the authorship requirements of this article are listed as authors; all coauthors are fully responsible for this work in its entirety.

Declaration of originality: the author assures that future republication will only take place with the express indication of the reference of this original publication; he also attests that there is no third party plagiarism. The text here published is a translation of: Il procedimento penale per fatti di criminalità organizzata: dal maxi-processo al «grande processo». Rivista Politica del Diritto, anno XXV, n. 3, setembro de 1994, pp. 385398; translation from Italian to Portuguese by Luiz Eduardo Cani. 


\section{Editorial process dates}

(http://www.ibraspp.com.br/revista/index.php/RBDPP/about/editorialPolicies)

- Submission: 24/05/2021

- Desk review: 01/06/2021

- Final editorial decision: 08/06/2021

\section{Editorial team}

- Editor-in-chief: 1 (VGV)

- Associated-editor: 1 (BC)

\section{HOW TO CITE (ABNT BRAZIL):}

ORLANDI, Renzo. O procedimento penal por fatos de criminalidade organizada: do maxi-processo ao "grande processo». Revista Brasileira de Direito Processual Penal, vol. 7, n. 3, p. 2105-2126, set./dez. 2021. https://doi.org/10.22197/rbdpp.v7i3.634 